\title{
Application of Response Surface Methodology for Optimizing Methyl Ester (Biodiesel) Production from Cotton Seed Oil
}

\author{
*T. Harsha Vardhan* \\ * Correspondence Author \\ M. Tech IPCE, \\ Dept. of Chemical Engineering, AUCE(A), \\ Andhra University, Visakhapatnam, \\ Andhra Pradesh, India
}

\author{
P. Venkata Rao \\ Assistant Professor, \\ Dept. of Chemical Engineering, AUCE(A), \\ Andhra University, Visakhapatnam, \\ Andhra Pradesh, India

\section{Sridevi} \\ Professor, \\ Dept. of Chemical Engineering, AUCE(A), \\ Andhra University, Visakhapatnam, \\ Andhra Pradesh, India
}

\begin{abstract}
Bio fuels such as biodiesel and biogas were increasing attention all over the world as alternative for fossil fuels in automobiles. Transesterification is the process that is used for producing biodiesel which is accepted because of its efficiency. Transesterification is the process done for decreasing the viscosity of the vegetable oil. The reaction variables used were methanol/oil molar ratio (3:1-9:1), catalyst concentration (0.5$2 \%$ ), temperature $\left(40-70^{\circ} \mathrm{C}\right)$, and catalyst type. The biodiesel with best yield and quality was produced in case of cotton seed methyl ester, at 6:1 methanol/oil molar ratio and $1 \mathrm{wt} \%$ of catalyst $(\mathrm{NaOH})$ the yield was $92.44 \%$ at $60^{\circ} \mathrm{C}$ temperature. The quality of the methyl ester produced is analysed by Gas Chromatography-Mass Spectroscopy (GC-MS) and Fourier Transform Infrared Spectroscopy (FTIR). FTIR and GC-MS analysis are studied to identify and confirm the presence of functional groups and fatty acid methyl esters. In this paper, we have used Transesterification of cottonseed oil to produce methyl ester using the catalyst $\mathrm{H}_{2} \mathrm{SO}_{4}$ and $\mathrm{NaOH}$. This was optimized by using the box-behnken design approach of response surface methodology (RSM). The different parameters for the optimization of methyl ester production were investigated. Response surface Methodology is used for the optimization of parameters in Design Expert 12 software. The results attained from the experimental runs were modeled and analyzed by choosing a quadratic model. The results obtained from the analysis of variance (ANOVA) of the model developed for the percentage yield of methyl ester as a function of molar ratio, amount of catalyst and reaction time. The cost of production of one liter of methyl ester from cottonseed oil is slightly higher the cost of the diesel per liter.
\end{abstract}

Keywords: Cotton seed oil, Methyl ester, GCMS, FTIR, Box Behnken method Design Expert 12
Shaik Gouse Mohiddin

M. Tech IPCE,

Dept. of Chemical Engineering, AUCE(A), Andhra University, Visakhapatnam, Andhra Pradesh, India

\author{
P. Srinu \\ M. Tech IPCE, \\ Dept. of Chemical Engineering, AUCE(A), \\ Andhra University, Visakhapatnam, \\ Andhra Pradesh, India
}

\section{INTRODUCTION}

Methyl ester is one of the alternative fuels that can be used as a substitution for diesel or as a blend with diesel in order to use it on diesel engines. Methyl ester can be produced from vegetable oils using various methods like micro emulsification method, microwave method, pyrolysis and Transesterification [1]. The Transesterification got global attraction among all the processes as it gives maximum efficiency.

For decreasing the viscosity of the vegetable oil transesterification method is used. Methanol is used as alcohol for transesterification since it is of low cost compared to other. Methyl ester is one of the promising alternative renewable energy sources for petroleum based diesel fuel [2].

The global demand of edible oil sources is increasing every year. Due to the "food verses fuel" problem, use of edible oil as a fuel source for transportation/ industry may not be viable, so the non-edible oils such as mahua (Madhuca indica), Jatropha (Jatropha curcas), Karanja (Pongamia pinnata), Cotton seed oil and Castor (Ricinus communis) can be used for methyl ester production. Since methyl ester is oxygenated, diesel engines have more complete combustion with bio-diesel than with petroleum. Methyl Ester is safer to use than petroleum diesel [3-4]. The use of bio-diesel in a conventional diesel engine results reduction of unburnt hydrocarbons, carbon monoxide, and particulate matter. The use of bio-diesel eliminates the sulphate fraction (as there is no sulphur in the fuel), decreases the solid carbon fraction of particulate matter (since the oxygen in bio-diesel enables more complete combustion to $\mathrm{CO}_{2}$ ), while the hydrocarbon fraction stays 
the same or is increased. Methyl Ester contains no petroleum, but it can be blended at any level with petroleum diesel to create a bio-diesel blend. Methyl ester is simple to use, nontoxic, biodegradable and essentially free of sulphur and aromatics. Methyl ester refers to the pure fuel before blending with diesel fuel [5-7].

Regardless of the feedstock used for methyl ester production, a catalyst is required to complete the process in a reasonable time. In other words, a catalyst is essential to improve the reaction rate and yield. The conventional catalysts used are homogeneous and heterogeneous catalysts depending upon the nature of feedstock used for the methyl ester production. Another catalyst being studied is biocatalyst (lipase) [8]. There are many studies for the alcoholysis of triglycerides using homogeneous catalysts [911]. For homogeneous catalysts, eminent conversions are easy to acquire in lesser than an hour of reaction at temperatures from 40 to $65^{\circ} \mathrm{C}$ [12]. Moreover, the transesterification process is strongly influenced by several factors including free fatty acid content in feedstock, molar ratio of oil to alcohol, catalyst concentration, stirring speed, reaction time, and temperature [13]. Optimization study for methyl ester production is important to assist researchers to establish a most adequate and cost effective-system in methyl ester industry [14]. The optimization studies of transesterification process using Response Surface Methodology (RSM) has been carried out by the researchers. Therefore, the main objectives of this work is to evaluate the effect of transesterification process parameters like molar ratio of oil to alcohol, catalyst concentration, and time on the percentage yield of cottonseed oil methyl esters and to find the optimum values of the selected factors using Response Surface Methodology(RSM). Response surface methodology is a combination of mathematical and statistical techniques which is widely used for designing experiments, building models, determining optimum conditions and evaluating the relative significance of several factors affecting a process. The experimental work performed and reported in this paper was aimed at obtaining the optimal production conditions for base catalyzed transesterication of methyl ester from cotton seed oil. The research objective was specifically to study the interaction effect of the parameters of methanol to oil molar ratio, catalyst weight, temperature and reaction time on transesterication of oil.

\section{MATERIALS AND METHODS}

Raw materials used in production of methyl ester are cottonseed oil. Cotton seeds were purchased at Guntur market and used in the extraction of oil. Cotton seed oil was obtained from seeds of cotton after refining process. These materials contain triglycerides, free fatty acids, and other contaminants.

\section{A. Collection of Reagents}

Methanol (99.5\% purity) of Thermo Fisher Scientific private Ltd., Sodium Hydroxide and Sulfuric acid of Merck Life Science Pvt. Ltd. were used in the experimental work.

\section{B. Preconditioning of cotton seed oil}

Preconditioning of oil used to remove the moisture and neutralization of free fatty acids (FFA. Removal of moisture involved heating the oil sample up to $105-120{ }^{\circ} \mathrm{C}$ and maintaining it there for few minutes so that all moisture gets evaporated.

\section{Methodology}

The transesterification reaction is one of the best way for carrying out the reaction for the production of methyl ester [8]. In the laboratory scale, the transesterification of cottonseed oil was carried out in three neck bottom flask of $2000 \mathrm{ml}$ capacity. The flask contains a magnetic needle and solution mixture and then it was placed on the magnetic stirrer. The flask has three openings from which side opening for reflux condenser.

The alcohol (Methanol) is volatile which is vaporized during the reaction, so reflux condenser is used to taper such that vapours return back into the flask. The other side opening is for thermometer and used to monitor the temperature continuously during the reaction and third for filling the reactants into the flask.

The treated oil is taken and heated to $60^{\circ} \mathrm{C}$ to melt the solid fats present in the oil. Methanol is added to the heated oil and it is stirred for five to ten minutes. One milliliter of $95 \%$ pure sulfuric acid $\left(\mathrm{H}_{2} \mathrm{SO}_{4}\right)$ is added and the compound is stirred for one hour maintaining the temperature at $60^{\circ} \mathrm{C}$. Heating is stopped and the mixture is stirred for another hour and the mixture is allowed to settle for eight hours in a decanter to remove glycerin.

The sodium methoxide is prepared with the oil and the sodium hydroxide, for each liter of oil/fat 0.12 liter of methanol (12\%by volume) is measured to which it is added 6.5 grams/liter of $\mathrm{NaOH}$. Half of the prepared sodium methoxide is poured into the unheated mixture and the mixture is stirred for five minutes and this will neutralize the sulfuric acid. The whole reaction is maintained at $60^{\circ}$ and the remaining sodium methoxide is added to the heated mixture and stirred at low speed of not more than 500 to 600 $\mathrm{rpm}$. After one hour the mixture is poured into a decanter and allowed it to settle for 8 hours. The glycerin will settle at the bottom as glycerin is heavier than the methyl ester.

Bubble wash method is used, but there is no need to monitor $\mathrm{pH}$ value of the oil, one $\mathrm{ml}$ of phosphoric acid $\left(\mathrm{H}_{3} \mathrm{PO}_{4}\right)$ is added to the washing water first and one third water by volume to the oil is being used and the oil is bubble washed for two hours. The mixture is allowed to settle in a decanter for one hour and the water is drained off. The methyl ester is heated to $100^{\circ} \mathrm{C}$ to dispense the traces of water.

Calculation of Yield:

$\begin{aligned} \text { Yield } & =\frac{\text { weight of cotton seed oil methyl ester }}{\text { weight of cotton seed oil }} \times 100 \\ & =\frac{323.79}{350.24} \times 100=92.44 \%\end{aligned}$

\section{Influence of Parameters}

\section{RESULTS AND DISCUSSION}

The experimental studies include the effect of catalyst concentrations in the range of 0.5 to $1.5 \mathrm{wt} \%$, the effect of 
temperature in the range $40-70^{\circ} \mathrm{C}$, the effect of reaction time in the range $30-120 \mathrm{~min}$, and the effect of mole ratio (oil to alcohol) in the range of $3: 1$ to $9: 1$

The optimum process parameters are obtained by conducting the experimental runs, in which one parameter is varying and the others are kept constant. The optimum values from the graphs are noted at which highest yield\% is obtained.

\section{A. Influence of Catalyst concentration on methyl ester yield:}

After pretreatment process, the cotton seed oil is used with 7:1 molar ratio of alcohol to oil, 1 wt $\%$ of $\mathrm{NaOH}$ catalysts and $90 \mathrm{~min}$ reaction time at $60^{\circ} \mathrm{C}$. In that, $\mathrm{NaOH}$ is frequently soluble in solvent and easily promote the reaction.

$\mathrm{NaOH}$ catalyst is used with $0.5,1.0,1.5$ and 2.0 wt \% concentration. For 2.0 wt. \% catalyst shows methyl ester yield to $78 \%$ decreases due to its higher concentration of catalyst addition gives negative effect of methyl ester production. Whereas 1.0 wt. \% of catalyst shows $92 \%$ methyl ester yield.

The addition of excess alkaline catalysts caused more triglycerides participation in the saponification reaction, resulting in increased production of soap and reduction of the esters yield. So, any increase in concentration of catalyst beyond the neutralization limit results in decrease in methyl ester conversion. The yields of CSME at different catalyst concentrations was shown in conversion graph Fig.1

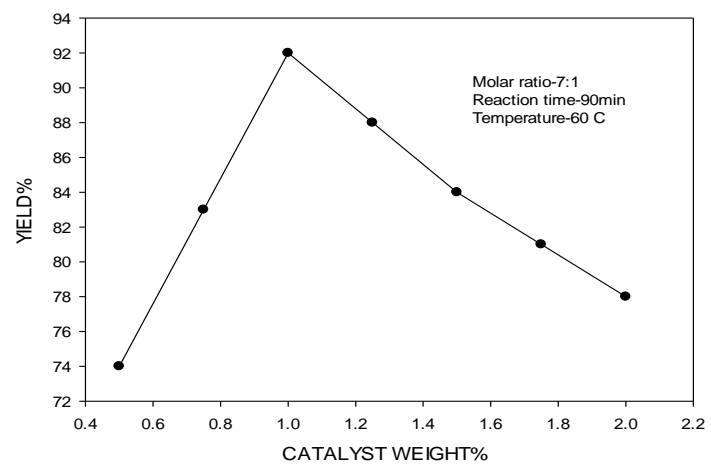

Fig. 1 Methyl ester yield with catalyst concentrations

\section{B. Influence of Temperature on methyl ester yield:}

The main advantage of higher temperatures influences to reduce reaction time. However higher reaction temperatures causes methanol to vaporize resulting in decreased yield. In this process, the temperature ranges used 40, 45, 50, 55, 60, 65 and $70^{\circ} \mathrm{C}$ and in order to optimize methyl ester yield with using the constant parameters are, alcohols to oil molar ratio of 7:1 with $\mathrm{NaOH}$ concentration of $1 \mathrm{wt}$. \% and at 90 min reaction time. At $50^{\circ} \mathrm{C}$ methyl ester yield was $83 \%$. Further the temperature increases to $60^{\circ} \mathrm{C}$, the methyl ester yield was $91 \%$. When the temperature decreases, the rate of reaction also decreases. The equilibrium concentration was strongly conditioned by the temperature. Therefore the optimum temperature is $60^{\circ} \mathrm{C}$. The yields of CSME at different temperatures was shown in conversion graph Fig.2

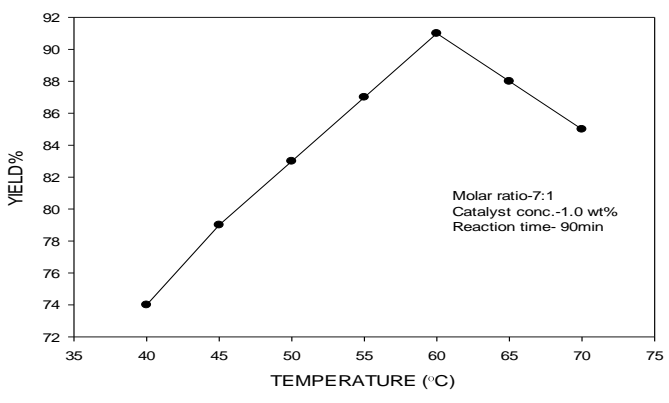

Fig. 2 Methyl ester yield with temperature

\section{Influence of Reaction Time on methyl ester yield:}

According to many researchers, the methyl ester yield is directly proportional to the reaction times used. This experiment was conducted from the reaction time of 30 to 120 min with the constant parameters: $60^{\circ} \mathrm{C}$ of reaction temperature for $1 \mathrm{wt} \%$ of $\mathrm{NaOH}$ catalyst used in 7:1 molar ratio. The longer mixing gives higher yield than using shorter time. So, $90 \mathrm{~min}$ of reaction time gave a good result than other reaction times used here. The methyl ester yield increases with increasing the reaction time. This undesirable result may be due to the higher soap formation when longer reaction time was used. The yields of CSME was shown in conversion graph Fig.3

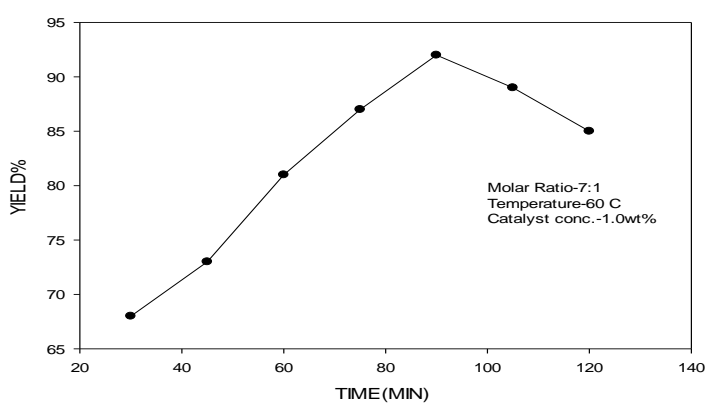

Fig.3 Methyl ester yield with reaction time

\section{Influence of Molar Ratio on methyl ester yield:}

In this experimental run, cottonseed oil were used with varying molar ratios of methanol to oil $(3: 1,4: 1,5: 1,6: 1,7: 1,8: 1$ and $9: 1)$ and $1.0 \mathrm{wt} \% \mathrm{NaOH}$ at $60^{\circ} \mathrm{C}$ with 90 min reaction time. If the molar ratio increased from $3: 1$ to $7: 1$ and then methyl ester yield content also increased. Now, molar ratio increases from 7:1 to 9:1, methyl esters content decreased. Excess of methanol is required to shift the equilibrium favorably during transesterification for better yields of methyl ester. The molar ratio $6: 1$ gives a better result than other molar ratios. The yield of CSME was shown in conversion graph shown in fig. 4 


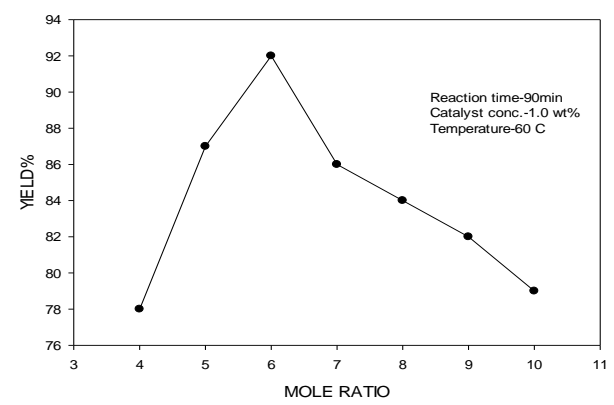

Fig.4 Methyl ester yield with molar ratio

\section{E. FFA Analysis of methyl ester using GC-MS}

The fatty acid composition of the oils seems to have an important role in the performance of the methyl ester in diesel engines. Based on the fatty acid composition and many other parameters the methyl ester specifications will be mandatory to limit the oxidative stability, as it may be a crucial parameter for injection pump performances. Moreover, the stability of the fuel is a quality parameter established by the ANP- National Petroleum Agency in Brazil, being its evaluation and control necessary. Vegetable oils are natural products consisting of ester mixtures derived from glycerol (triglyceride), whose chains of fatty acid contain about 14 to 20 carbon atoms with different degrees of unsaturation.

The transesterification reaction consists in the conversion of the triglyceride molecules, by means of the action of short chain alcohol, i.e., methanol, ethanol into the corresponding fatty acid esters. The prepared Methyl Ester i.e. CSME (Cotton seed oil methyl ester) was analyzed by GC-MS system to determine the composition of fatty acids.

The methyl ester is mainly formed by transesterification of saturated and monounsaturated fatty acids while the remaining polyunsaturated and some bulk saturated fatty acid are responsible for high viscosity. The higher level of unsaturated fatty acid reduces fuel quality, because of its easy oxidation. The GC-MS report of methyl esters was shown in Fig.5.

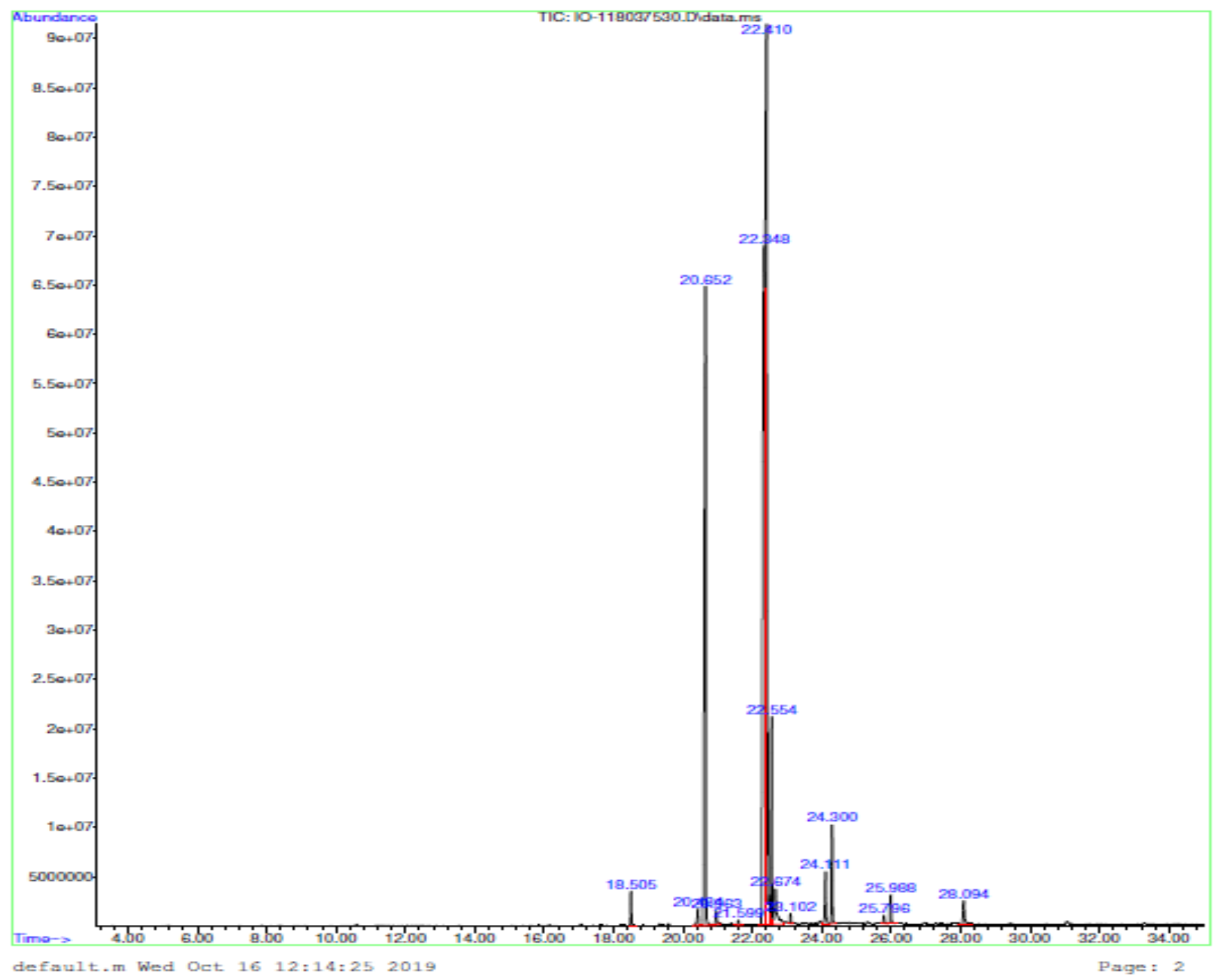

Fig.5 GC-MS Analysis for the Methyl ester of Cotton Seed oil 


\section{F. Fourier Transform Infrared Spectroscopy (FTIR) Analysis}

The methyl ester obtained from the cotton seed oil after the transesterification process is sent for FTIR analysis and the results obtained in Fig.6.

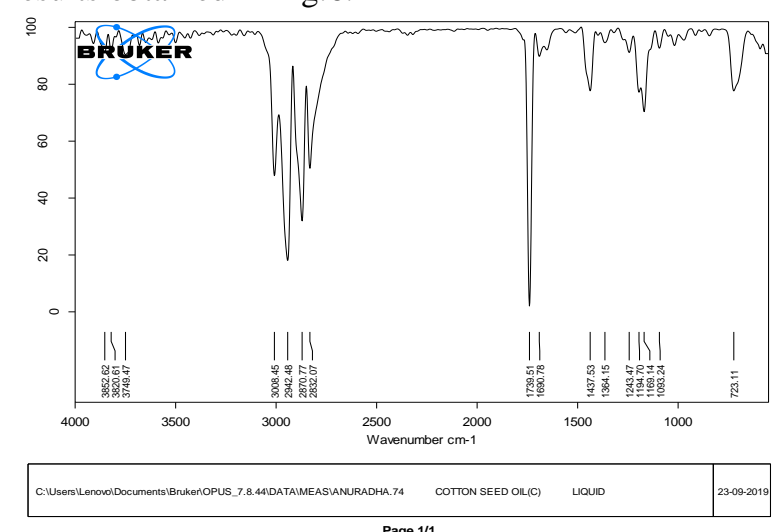

Fig.6 FTIR Spectra of CSME
FTIR is used to determine the functional groups such as alcohol, alkane, alkynes, alkenes and other such groups present in the sample. Fig.6 and Table-I shows spectra and FTIR studies of CSME.

Table-I FTIR Studies of CSME

\begin{tabular}{|c|c|c|c|c|c|c|}
\hline S.NO. & Peaks $\left(\mathrm{cm}^{-1}\right)$ & Bond & Compound Type & Mode & Transmittance $(\%)$ & Concentration \\
\hline 1 & 3008.45 & $\begin{array}{l}\mathrm{C}-\mathrm{H}, \\
=\mathrm{C}-\mathrm{H}\end{array}$ & $\begin{array}{l}\text { aromatics, } \\
\text { alkenes }\end{array}$ & Stretch & 58 & Strong, medium \\
\hline 2 & 2942.48 & $\begin{array}{l}\mathrm{O}-\mathrm{H} / \\
\mathrm{C}-\mathrm{H}\end{array}$ & $\begin{array}{c}\text { carboxylic } \\
\text { acid/alkanes }\end{array}$ & Stretch & 17 & Medium \\
\hline 3 & 2870.77 & $\begin{array}{l}\mathrm{O}-\mathrm{H} / \\
\mathrm{C}-\mathrm{H}\end{array}$ & $\begin{array}{c}\text { carboxylic } \\
\text { acid/alkanes }\end{array}$ & Stretch & 32 & Medium \\
\hline 4 & 2832.07 & $\begin{array}{l}\mathrm{O}-\mathrm{H} / \\
\mathrm{C}-\mathrm{H}\end{array}$ & $\begin{array}{c}\text { carboxylic } \\
\text { acid/alkanes }\end{array}$ & Stretch & 52 & Medium \\
\hline 5 & 1739.51 & $\mathrm{C}=\mathrm{O}$ & $\begin{array}{l}\text { carboxylic acids/ } \\
\text { carbonyls/ esters }\end{array}$ & Stretch & 12 & Strong \\
\hline 6 & 1437.53 & $\begin{array}{l}\mathrm{C}-\mathrm{C} / \\
\mathrm{C}-\mathrm{H}\end{array}$ & $\begin{array}{l}\text { aromatics/ } \\
\text { Alkanes }\end{array}$ & $\begin{array}{c}\text { stretch/ } \\
\text { bend }\end{array}$ & 74 & Medium \\
\hline 7 & 1364.15 & $\mathrm{C}-\mathrm{H}$ & Alkanes & Rock & 78 & Medium \\
\hline 8 & 1243.47 & $\mathrm{C}-\mathrm{N}$ & $\begin{array}{l}\text { Aliphatic } \\
\text { Amines }\end{array}$ & Stretch & 85 & Medium \\
\hline 9 & 1194.70 & $\mathrm{C}-\mathrm{N}$ & $\begin{array}{l}\text { Aliphatic } \\
\text { Amines }\end{array}$ & Stretch & 70 & Medium \\
\hline 10 & 1169.14 & $\mathrm{C}-\mathrm{N}$ & $\begin{array}{l}\text { Aliphatic } \\
\text { Amines }\end{array}$ & Stretch & 68 & Medium \\
\hline 11 & 1093.24 & $\mathrm{C}-\mathrm{O}$ & $\begin{array}{c}\text { Alcohols/ } \\
\text { carboxylic acid }\end{array}$ & Stretch & 83 & Strong \\
\hline 12 & 723.11 & $\mathrm{C}-\mathrm{H}$ & Alkanes & Rock & 74 & Medium \\
\hline
\end{tabular}

\section{EXPERIMENTAL DESIGN}

Response surface methodology (RSM) was used to relate the three process variables Methanol to oil molar ratio, catalyst concentration and temperature with the response (methyl ester yield) and to determine the optimal combination of process variables that would maximize the methyl ester yield

A Three-factor BBM (Box-Behnken Model) based on 17 experimental runs at various numerical value of Methanol to oil molar ratio, catalyst concentration and temperature was conducted to investigate their main and interaction contribution on the \% yield, while keeping RPM and time as constant. The total number of experiments for the BBD was ascertained utilizing the accompanying condition: $\mathrm{N}=2 \mathrm{k}^{*}(\mathrm{k}-1)+\mathrm{Cp}$
Where $\mathrm{N}=$ number of trials; $\mathrm{k}=$ number of process variables; and $\mathrm{Cp}=$ centre points. Absolutely, 17 exploratory runs (4 axial, 8 factorial and 5-center points) were composed in view of the BBD matrix at three unique levels $(-1,0,1)$ of autonomous parameters (Table-II).

Table-II. Input variables and their ranges

\begin{tabular}{|l|l|l|l|l|l|}
\hline Name & Units & Type & $\begin{array}{l}\text { Std. } \\
\text { Dev }\end{array}$ & Low & High \\
\hline $\begin{array}{l}\text { Methanol to oil } \\
\text { molar ratio }\end{array}$ & - & Factor & 0 & 5 & 7 \\
\hline Catalyst Weight \% & Wt.\% & Factor & 0 & 0.5 & 1.5 \\
\hline Temperature & ${ }^{0} \mathrm{C}$ & Factor & 0 & 50 & 70 \\
\hline Yield & $\%$ & Response & 0.5039 & 86.3 & 92.44 \\
\hline
\end{tabular}


Table-III. Experimental Design by Box-Behnken design

\begin{tabular}{|c|c|c|c|c|c|c|}
\hline Std & Run & $\begin{array}{l}\text { Methanol to oil } \\
\text { ratio }\end{array}$ & Catalyst weight $\%$ & Temperature ${ }^{0} \mathrm{C}$ & Actual Yield \% & $\begin{array}{c}\text { Predicted Yield } \\
\%\end{array}$ \\
\hline 15 & 1 & 6 & 1 & 60 & 92.44 & 92.44 \\
\hline 7 & 2 & 5 & 1 & 70 & 86.9 & 87.19 \\
\hline 5 & 3 & 5 & 1 & 50 & 85.6 & 86.08 \\
\hline 2 & 4 & 7 & 0.5 & 60 & 87.7 & 87.99 \\
\hline 3 & 5 & 5 & 1.5 & 60 & 86.8 & 86.51 \\
\hline 14 & 6 & 6 & 1 & 60 & 92.44 & 92.44 \\
\hline 1 & 7 & 5 & 0.5 & 60 & 86 & 85.52 \\
\hline 11 & 8 & 6 & 0.5 & 70 & 89.78 & 89.97 \\
\hline 6 & 9 & 7 & 1 & 50 & 87.3 & 87.01 \\
\hline 9 & 10 & 6 & 0.5 & 50 & 90.2 & 90.20 \\
\hline 13 & 11 & 6 & 1 & 60 & 92.44 & 92.44 \\
\hline 8 & 12 & 7 & 1 & 70 & 89.5 & 89.02 \\
\hline 16 & 13 & 6 & 1 & 60 & 92.44 & 92.44 \\
\hline 4 & 14 & 7 & 1.5 & 60 & 86.3 & 86.78 \\
\hline 10 & 15 & 6 & 1.5 & 50 & 88.5 & 88.31 \\
\hline 12 & 16 & 6 & 1.5 & 70 & 91.65 & 91.65 \\
\hline 17 & 17 & 6 & 1 & 60 & 92.44 & 92.44 \\
\hline
\end{tabular}

From the table it can be observed that the minimum and maximum of methyl ester were obtained at 3 and 11 respectively as 85.6 and 92.44 .

\section{A. Model fitting statistics}

As discussed in previous section, for optimization of transesterification process of cottonseed oil, three process parameters namely; molar ration, amount of catalyst and conversion time were investigated.

Response surface methodology (RSM) was used to relate the three process variables Methanol to oil molar ratio, catalyst concentration and temperature with the response (methyl ester yield) and to determine the optimal combination of process variables that would maximize the methyl ester yield

A Three-factor BBM (Box-Behnken Model) based on 17 experimental runs at various numerical value of Methanol to oil molar ratio, catalyst concentration and temperature was conducted to investigate their main and interaction contribution on the \% yield, while keeping RPM and time as constant. The coded and uncoded levels of independent factors according to 17 experiments correspond to BBM along their responses are as follows,(Table-III).

The total number of experiments for the BBD was ascertained utilizing the accompanying condition:

$\mathrm{N}=2 \mathrm{k}^{*}(\mathrm{k}-1)+\mathrm{Cp}$

Where $\mathrm{N}=$ number of trials; $\mathrm{k}=$ number of process variables; and $\mathrm{Cp}=$ centre points. Absolutely, 17 exploratory runs (4 axial, 8 factorial and 5-center points) were composed in view of the $\mathrm{BBD}$ matrix at three unique levels $(-1,0,1)$ of autonomous parameters

B. Final Equation in Terms of Coded Factors:

Yield $=+92.44+0.6875 \mathrm{~A}-0.0537 \mathrm{~B}+0.7788 \mathrm{C}-0.5500 \mathrm{AB}$ $+0.2250 \mathrm{AC}+0.8925 \mathrm{BC}-4.22 \mathrm{~A}^{2}-1.52 \mathrm{~B}^{2}-0.8912 \mathrm{C}^{2}$ -------- (1)

C. Final Equation in Terms of Actual Factors:

Yield $=-94.24500+$ 51.12250Molar Ratio +7.91250Catalyst Weight $\%$ +0.833875Temperature1.10000Molar Ratio * Catalyst Weight $\%+0.022500$ Molar Ratio * Temperature+0.178500Catalyst Weight\% * Temperature -4.22375 Molar Ratio²-6.06500Catalyst Weight\%²-0.008913Temperature ${ }^{2}$

D. Analysis of Variance (ANOVA):

The ANOVA - developed for \% Yield and results are displayed in table-IV. Quality of the Quadratic Model for the yield using Box-Behnken Design is shown in table-V. The Model F-value of 61.86 implies the model is significant. There is only a $0.01 \%$ chance that a "Model F-Value" this large could occur due to noise. Values of "Prob $>F$ less than 0.0500 indicate model terms are significant. In this case A, $\mathrm{B}, \mathrm{C}, \mathrm{AB}, \mathrm{AC}, \mathrm{BC}, \mathrm{A}^{2}, \mathrm{~B}^{2}, \mathrm{C}^{2}$ are significant model terms. Values greater than 0.1000 indicate the model terms are not significant. If there are many insignificant model terms (not counting those required to support hierarchy), model reduction may improve your model. The "Lack of Fit Fvalue" of 16.10 implies the Lack of Fit is significant. There is only a $1.07 \%$ chance that a "Lack of Fit F-value" this large could occur due to noise. Significant lack of fit is bad we want the model to fit. 
Table IV ANOVA Table for Model to Predict yield\% using Box-Behnken Design

\begin{tabular}{|c|c|c|c|c|c|c|}
\hline \multicolumn{7}{|c|}{$\begin{array}{c}\text { ANOVA for Response Surface Quadratic Model } \\
\text { Analysis of variance table[Partial sum of squares-Type III] }\end{array}$} \\
\hline Source & Sum of Squares & df & Mean Square & F-value & p-value & \\
\hline Model & 107.34 & 9 & 11.93 & 61.86 & $<0.0001$ & significant \\
\hline A-Molar Ratio & 3.78 & 1 & 3.78 & 19.61 & 0.0030 & \\
\hline B-Catalyst Weight $\%$ & 0.0231 & 1 & 0.0231 & 0.1199 & 0.7393 & \\
\hline C-Temperature & 4.85 & 1 & 4.85 & 25.17 & 0.0015 & \\
\hline $\mathrm{AB}$ & 1.21 & 1 & 1.21 & 6.28 & 0.0407 & \\
\hline $\mathrm{AC}$ & 0.2025 & 1 & 0.2025 & 1.05 & 0.3395 & \\
\hline $\mathrm{BC}$ & 3.19 & 1 & 3.19 & 16.53 & 0.0048 & \\
\hline $\mathrm{A}^{2}$ & 75.12 & 1 & 75.12 & 389.64 & $<0.0001$ & \\
\hline $\mathrm{B}^{2}$ & 9.68 & 1 & 9.68 & 50.21 & 0.0002 & \\
\hline $\mathrm{C}^{2}$ & 3.34 & 1 & 3.34 & 17.35 & 0.0042 & \\
\hline Residual & 1.35 & 7 & 0.1928 & & & \\
\hline Lack of Fit & 1.35 & 3 & 0.4498 & & & \\
\hline Pure Error & 0.0000 & 4 & 0.0000 & & & \\
\hline Cor Total & 108.68 & 16 & & & & \\
\hline
\end{tabular}

Table-V Quality of the Quadratic Model for the yield using Box-Behnken

\begin{tabular}{|l|l|l|l|}
\hline Std. Dev. & 0.4391 & $\mathbf{R}^{2}$ & 0.9876 \\
\hline Mean & 89.32 & Adjusted $\mathbf{R}^{2}$ & 0.9716 \\
\hline C.V. \% & 0.4912 & Predicted $\mathbf{R}^{2}$ & 0.8013 \\
\hline & & Adeq Precision & 20.5604 \\
\hline
\end{tabular}

The Predicted $\mathrm{R}^{2}$ of 0.8013 is in reasonable agreement with the Adjusted $\mathrm{R}^{2}$ of 0.9716 ; i.e. the difference is less than 0.2. Adeq Precision measures the signal to noise ratio. A ratio greater than 4 is desirable. Your ratio of 20.560 indicates an adequate signal. This model can be used to navigate the design space. The following fig.7 was drawn between predicted and experimental values of \% yield using Design expert. Almost all points were coincided with each other with very small deviation. The surface contour plots of cotton seed oil, between the effect of methanol to oil molar ratio, catalyst concentration and temperature on \% Yield are shown in fig.8, 9 and 10 .

\section{E. Model diagnostic plot}

The predicted values of response were plotted against the actual response values, which were obtained from experimentations, see Fig.7. It can be deduced that the diagnostic plot, i.e. Fig.7, indicates a linear relationship between the actual and predicted values that shows the adequacy of the proposed model.
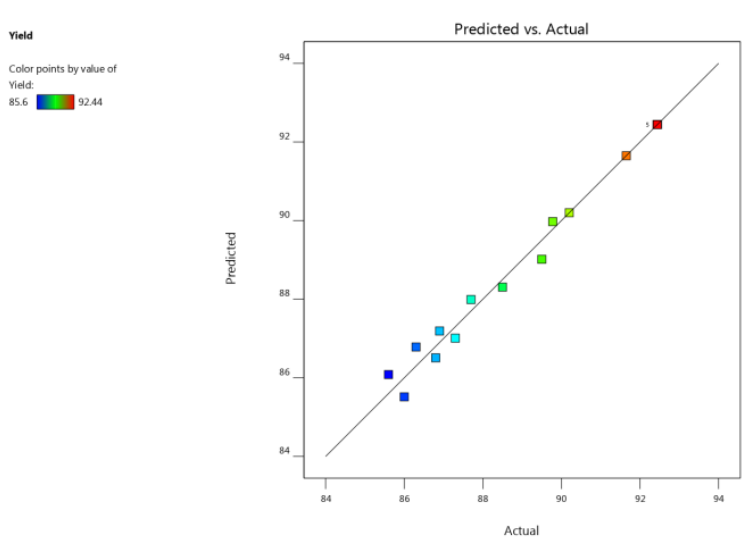

Fig.7 Predicted vs Actual Yield

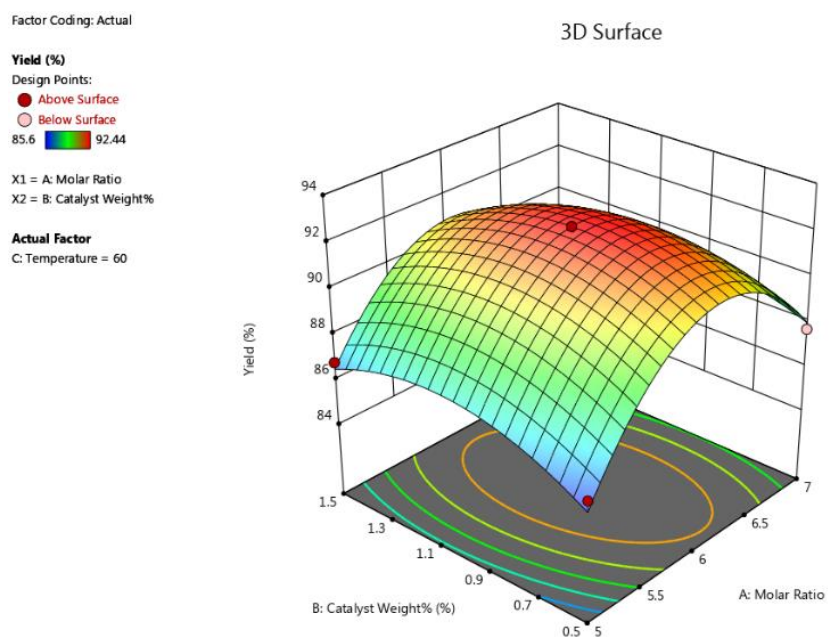

Fig. 8 Surface contour plot for the effect of methanol to oil molar ratio and catalyst weight $\%$ on yield $\%$ 


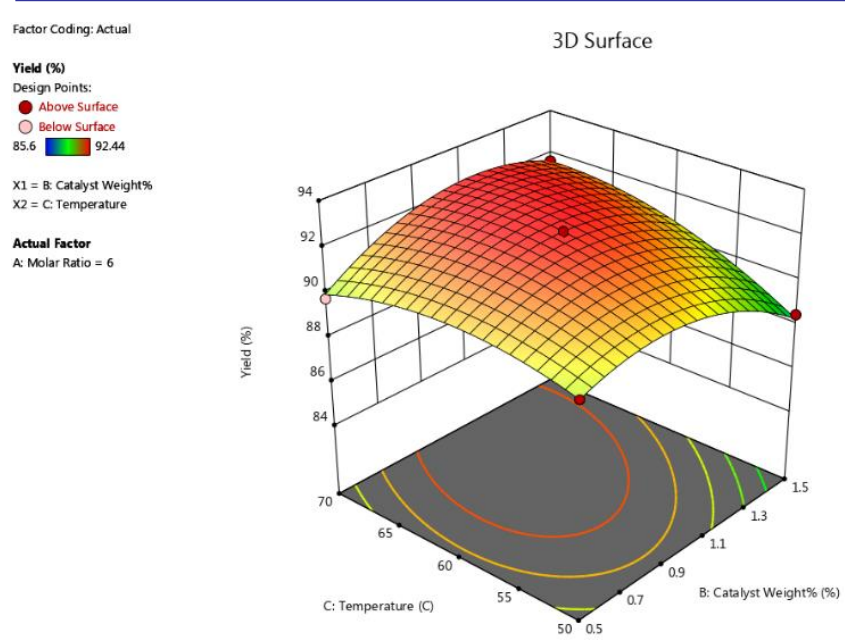

Fig.9 Surface contour plot for the effect of temperature and catalyst weight $\%$ on yield $\%$

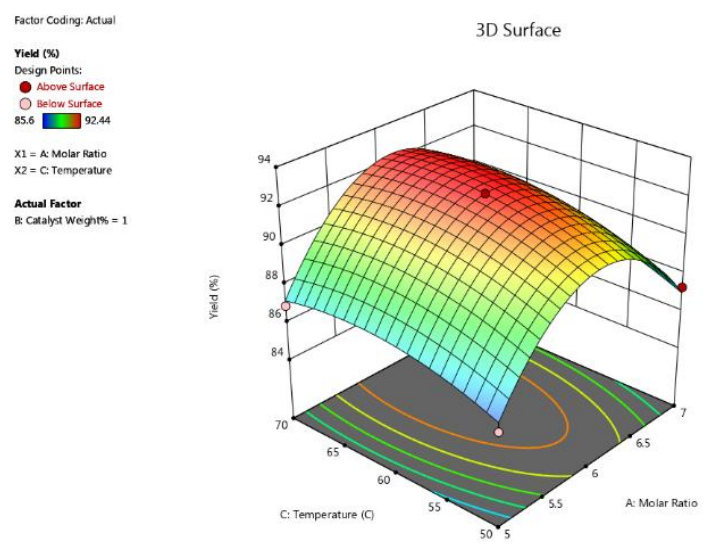

Fig.10 Surface contour plot for the effect of methanol to oil molar ratio and temperature on yield $\%$

\section{F. Response Surface Plots}

The 3D response surface plots of the proposed model have been shown in Fig.7 to Fig.10 that represents the analysis of interaction effects of the preferred variables. The $3 \mathrm{D}$ surface plot of response, Fig.8, indicates the effect of interaction of molar ratio and catalyst concentration on percentage of yield of cottonseed oil methyl ester. In fig.9, 3D surface plot of response indicates the effect of interaction of temperature and catalyst concentration on percentage of yield of methyl ester. 3D surface plot of response, fig.10, indicates the effect the effect of methanol to oil molar ratio and temperature on $\%$ yield on percentage of yield of cottonseed oil methyl ester.

The optimum values of molar ratio, amount of catalyst and reaction time have been found as $6: 1,1.0(\% \mathrm{wt})$, and $60 \mathrm{~min}$ respectively, when predicted oil recovery is $92.44 \%$.The confirmatory experimental run was performed at optimum values of variables and was verified.

\section{CONCLUSION}

The effects of different parameters such as reaction time, temperature, catalyst, concentration and reactant ratio on the methyl ester yield were analyzed. CSME was analyzed by GC-MS system to determine the composition of fatty acids. From FTIR analysis it is observed that the bonds such as C-
$\mathrm{H}, \mathrm{C}-\mathrm{O}, \mathrm{O}-\mathrm{H}$ and $\mathrm{C}-\mathrm{N}$ are abundant in cotton seed oil methyl ester. The modes of the bonds are stretch, bending and rocking. The optimization parameters of transesterification of cottonseed oil were performed. The process parameters, like molar ratio (A), amount of catalyst (B) and reaction time (C) were optimized using RSM under Box-Behnken design. For optimization, a quadratic model was developed and validated. Analysis of Variance (ANOVA) was performed, which indicates that the three linear terms has the more significant effect on percentage of yield, further one cross product term $(\mathrm{AB})$ and one quadratic term $(\mathrm{A} 2)$ were found significant. The maximum cottonseed oil methyl ester yield of $92.44 \%$ was determined when molar ratio, catalyst concentration and reaction time, were 6:1, 1.0 (\%wt) and 1 $\mathrm{hr}$ respectively. Finally it was concluded that the process parameter optimization using RSM under Box-Behnken design provides better cottonseed oil methyl ester yields.

\section{REFERENCES}

[1] SenthilKumar.R, Manimaran. R, Ramadoss. R. Performance Characteristics of a DI Diesel Engine Fuelled with the Blends of Diesel-Methyl ester-Ethanol. International Journal of Scientific \& Engineering Research, 2013, 4:240-245.

[2] Meher.L.C, VidyaSagarD. Technical aspects of methyl ester production by transesterification. Renewable and sustainable Energy Reviews, 2006, 10:248-268. 3.

[3] YusufN.N.A.N, KamarudinS.K, YaakubZ. Overview on the current trends in methyl ester production. Energy Conversion and Management, 2011, 52: 2741-2751.

[4] SharmaY.C, SinghB, UpadhyaS.N.Advancements in development and characterization of methyl ester A review, Fuel, 2008, 87:2355-2373.

[5] Aninidita K, Subrata K, Souti M. Properties of various plants and animals feedstocks for methyl ester production. Bioresource Technology,2010, 101:7201-7210. S. Chandra Sekhar et al /International Journal of ChemTech Research, 2017,10(5): 122130. 130

[6] Mukesh Kumar, M.P. Sharma Assessment of potential of oils for methyl ester production Renewable and Sustainable Energy Reviews, 2015,44 :814-823.

[7] Basumatary ,S. Non-Conventional Seed Oils as Potential Feedstocks for Future Methyl ester Industries: A Brief Review, Research Journal of Chemical Sciences, 2013, 3(5):99-103,

[8] NurSyakirah T and Sarina S.Overview of Catalysts in Methyl ester Production,, ARPN Journal of Engineering and Applied Sciences, 2016,11:439-448.

[9] Gemma V,Mercedes M,José A. Integrated methyl ester production: a comparison of different homogeneous catalysts systems,Bioresource Technology,2004, 92(3):297-305.

[10] HossainE A.B.M.S, MazenM.A.Effects of catalyst types and concentrations on methyl ester production from waste soybean oil biomass as renewable energy and environmental recycling process Australian Journal of Crop Sciences ,4(7) (2010):550-555.

[11] Cut A Z J, Abrar M. Performance of $\mathrm{KOH}$ as a catalyst for Transesterification of JatrophaCurcasOil, International Journal of Engineering Research and Applications, 2012,2(2): 635-639.

[12] GeorgogianniK.G, KontominasM.G,PomonisP.J, AvlonitisD, GergisV.Conventional and in situ transesterification of sunflower seed oil for the production of methyl ester, Fuel Process. Technol. 2008, 89:503-509.

[13] MathiyazhaganM and GanapathiA.Factors Affecting Methyl ester Production, Research in Plant Biology, 20111, 2:01-05.

[14] Wong.Y C, TanY.P., Taufiq-YapY.H.\&RamliI. An Optimization Study for Transesterification of Palm Oil using Response Surface Methodology (RSM), SainsMalaysiana, 2015, 44(2): 281-290. 


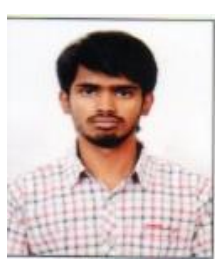

T Harsha Vardhan is a graduate in B.Tech (Chemical engineering) from JNTUA CEA, Anantapur. He also completed his M.Tech from the Department of Chemical Engineering, Andhra University, Visakhapatnam. Harsha Vardhan is extremely fascinated by the increasing growth in the field of Chemical Engineering, with an unceasing enthusiasm; he grabbed the opportunity to work as a summer internship trainee in Rayalaseema alkalies and allied Chemicals, Kurnool. Further, he has done his project on Extraction of caffeine from Tea leaves in B.Tech and Production of Biodiesel in M.Tech. He is highlydriven towards piloting more research studies in future and the current research paper is one of the indexes of his inquisitiveness

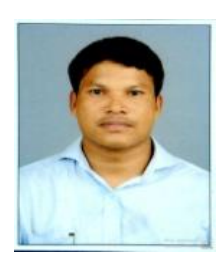

Mr. P.Venkat rao is Assistant Professor having an experience of 11 years in teaching and more than 10 years of Research experience from the Department of Chemical Engineering, Andhra University College of Engineering (A), Andhra University, Visakhapatnam. Mr.P.Venkat rao has significantly contributed in the field of Heat Transfer, Corrosion Engineering etc.. he has worked on Biosorption. He has successfully guided $28 \mathrm{M}$. Tech students and has published more than 4 papers in National \& International Journals.

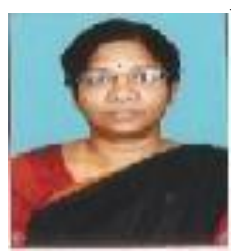

Dr. V. Sridevi is Professor having an experience of 21 years in teaching and more than 10 years of Research experience from the Department of Chemical Engineering, Andhra University College of Engineering (A), Andhra University, Visakhapatnam.

Dr. V. Sridevi has significantly contributed in the field of Industrial Pollution and Control Engg. She has worked on Biodegradation, Bio reactor design and Industrial Pollution \&amp; its control. She has successfully guided $40 \mathrm{M}$. Tech students and 13 Research scholars were pursuing PhD (03 Awarded \& 02 submitted) under her guidance. She has published more than 150 papers in National \& International Journals. She is serving as Quality Management System Internal auditor for ISO 9001:2015 certification. She is also serving as Departmental Research Committee member \&amp; a member of departmental development, Examinations committee and Industrial Training \& student activities. 